\title{
Foraging behaviour and prey consumption in the Indo-Pacific lionfish on Bahamian coral reefs
}

\author{
Stephanie J. Green ${ }^{1, *}$, John L. Akins ${ }^{2}$, Isabelle M. Côté ${ }^{1}$ \\ ${ }^{1}$ Department of Biological Sciences, Simon Fraser University, 8888 University Drive, Burnaby, British Columbia V5A 1S6, Canada \\ ${ }^{2}$ Reef Environmental Education Foundation, 98300 Overseas Highway, Key Largo, Florida 33037, USA
}

\begin{abstract}
Predicting and mitigating the effects of invasive Indo-Pacific lionfish Pterois volitans on Caribbean fish communities requires a thorough understanding of the species' predation behaviour in the invaded range, including the types and amounts of prey consumed and how foraging patterns vary in relation to extrinsic conditions. We studied the activity levels and prey consumption rates of lionfish on 12 shallow coral reefs in the Bahamas in relation to time of day and prey availability. Lionfish predation rates and activity levels were significantly higher during crepuscular (dawn and dusk) periods than at mid-day. Available prey fish biomass was highest at dawn but lower at mid-day and dusk, suggesting that lionfish predation activity is not limited by prey availability alone. Our calculated average daily mass-specific prey consumption rates, which incorporated daily variation, was $\sim 3$ times the estimates obtained from studies of captive lionfish in their native range and of invasive lionfish observed only during the day. Our results will help to predict more accurately the effect of predation by invasive lionfish on native reef fish communities.
\end{abstract}

KEY WORDS: Pterois volitans · Marine invasion $\cdot$ Predation rates · Daily pattern · Behavioural observations

Resale or republication not permitted without written consent of the publisher

\section{INTRODUCTION}

Species invasions are emerging as a top threat to marine systems globally and are occurring at an ever increasing pace (Mooney \& Cleland 2001, Goldberg \& Wilkinson 2004). There is growing concern that one recent invasion - that of the Indo-Pacific lionfish Pterois volitans across coral reefs in the Western Atlantic and Caribbean - will have extreme effects on regional biodiversity and fish production (Albins \& Hixon 2011, Green \& Côté 2009, Morris \& Whitfield 2009, Sutherland et al. 2010). Lionfish regularly prey on a wide array of native Caribbean fish species, including several of commercial importance (Morris \& Akins 2009). Efforts to predict and mitigate the effects of lionfish predation on Caribbean fish communities require a thorough understanding of the type and amount of prey they consume on invaded reefs.

Many extrinsic factors, such as prey size, density and predation risk, influence patterns and rates of pre- dation (Vincent \& Mori 2008). These factors are in turn influenced by spatial and temporal variation in abiotic environmental conditions (e.g. Sweatman 1984, Yamashita et al. 2005). In the marine realm, the daily cycle of light availability has a particularly strong influence on the foraging activities of most predators, with many species foraging most actively during low-light dawn and dusk 'crepuscular' periods (Hobson 1973, Helfman 1978, Galzin 1987). Species feeding under these conditions may benefit from increased prey availability, increased capture success or decreased detection by visual predators (Fishelson 1975, Helfman1993, Connell 1998).

To date, variation in lionfish foraging behaviour and predation rates across the day has not been investigated, but may have important consequences for estimating daily and annual prey consumption. For example, while lionfish are believed to hunt primarily during low-light crepuscular periods in their native range (Fishelson 1975, 1997), daytime observations of 
lionfish on Bahamian reefs have yielded estimates of prey consumption that far exceed anecdotal reports from the native range (Côté \& Maljković 2010). If the rates at which invasive lionfish consume prey are highest during crepuscular periods, a question not examined by Côté \& Maljković (2010), then lionfish prey consumption in their introduced range has been underestimated. In addition, a thorough understanding of the timing of lionfish foraging activity is important for the design of future diet studies so that sample collection may be conducted around times of high foraging activity.

The objectives of this study were to document the foraging patterns, activity levels and prey consumption rates of lionfish, as well as their available prey, at different times of the day on invaded Bahamian coral reefs. We addressed 2 specific questions: (1) Are lionfish prey consumption rates and activity levels significantly higher during low-light (crepuscular) hours than during mid-day periods? (2) Do high predation rates and activity levels by lionfish coincide with periods of higher prey availability? Accurate estimates of massspecific prey consumption rates are important because they can be used to examine the effect of lionfish on native prey populations. However, the only available estimates of lionfish prey consumption derive from daytime-only estimates (Côté \& Maljkovi 2010) and from bioenergetics studies of captive Pterois miles, the sister species of $P$. volitans in the Indian Ocean (Fishelson 1997). To illustrate the importance of incorporating daily variation in behaviour into estimates of prey consumption, we compared our own estimates of daily mass-specific prey consumption rates by lionfish to estimates from these 2 published studies.

\section{MATERIALS AND METHODS}

Study sites and data collection. In September 2008 and December 2009 we conducted detailed observations of lionfish behaviour, and estimated prey availability at dawn, mid-day and dusk, on 12 invaded coral reef patches off the Bahamian island of Eleuthera $\left(25^{\circ} 22.5^{\prime} \mathrm{N}, 76^{\circ} 49.0^{\prime} \mathrm{W}\right)$. Lionfish were first sighted around Eleuthera in 2005 (USGS Non-Indigenous Aquatic Species Database 2009 http://fl.biology.usgs. gov/lionfish_progression/lionfish_progression.html), and are now abundant on reefs around the island (http://www.reef.org, REEF 2011). The 12 sites were similar in terms of location and structure. Reefs were roughly circular, with similar areas (from 80 to $100 \mathrm{~m}^{2}$ ) and depths (from 3 to $5 \mathrm{~m}$ ). Each site was separated by at least $500 \mathrm{~m}$ of sand and seagrass from any other reef structure. Benthic structure was provided primarily by living and dead hard corals (from 60 to $80 \%$ of benthic composition) at all sites. Vertical relief, measured as the total height of the reef structure (to the nearest $\mathrm{cm}$ ) at 6 points per site (Luckhurst \& Luckhurst 1978), did not vary among sites (1-way ANOVA; $F=0.56$, df $=$ $11,66, \mathrm{p}=0.72$ ).

We observed lionfish on 6 reefs in September 2008 and on 6 other reefs in December 2009. In each season, we observed lionfish on 2 reefs at dawn, 2 at mid-day and 2 at dusk. Taking both seasons together, this resulted in 4 reefs being observed in each of the 3 time periods. Dawn observations covered the period from $1 \mathrm{~h}$ before to $1 \mathrm{~h}$ after sunrise, while dusk observations covered the period from $1 \mathrm{~h}$ before to $1 \mathrm{~h}$ after sunset. All mid-day observations occurred between 11:00 and 15:00 h. In September 2008, sunrise was at $\sim 07: 00 \mathrm{~h}$ and sunset at 19:00 h, and in December 2009, sunrise and sunset were at $\sim$ 7:00 and $\sim 17: 00 \mathrm{~h}$, respectively. Because lionfish were not individually marked, it was not possible to knowingly observe the same individual across different time periods, nor was it possible to observe only some individuals in one time period and the remainder in other periods. For this reason, all lionfish on a patch were observed in a single session during one of the 3 pre-determined periods of day. The number of lionfish on each patch varied between 5 and 12. Two or 3 trained observers, depending on the number of lionfish present, simultaneously observed different focal fish on a reef. Because prey consumption rates can be influenced by fish size (i.e. Fonds et al. 1992), we compared mean lionfish total length (TL) on reefs observed at the 3 times of day using a 1-way analysis of variance, and found no significant difference. Mean $\pm \mathrm{SD}$ at dawn was $22 \pm 6 \mathrm{~cm}$; at mid-day, 20 $\pm 6 \mathrm{~cm}$; at dusk, $24 \pm 9 \mathrm{~cm}(F=2.72, \mathrm{df}=2,89, \mathrm{p}=0.08)$.

All observations were conducted while on SCUBA at a distance of 2 to $3 \mathrm{~m}$ from focal lionfish. During a pilot study, observers at this distance appeared not to affect fish behaviour, yet still had an unobstructed view of the focal lionfish and its potential prey. Before observations began, we noted the distribution of lionfish at each study site to ensure that no individual was observed twice. Each lionfish was observed for $30 \mathrm{~min}$. At the beginning of each observation period, we estimated the TL of the fish to the nearest $\mathrm{cm}$. We noted all predation attempts during each $30 \mathrm{~min}$ period and identified the target of each attempt to the lowest taxonomic level possible. Hunting lionfish typically hover closely above a single prey item, often for several minutes, before striking, allowing ample time to identify the targeted species. Predation attempts were categorised as successful if the focal lionfish unambiguously consumed the prey fish, or unsuccessful if the prey fish either escaped or if the outcome of the attempt was uncertain. We also estimated and recorded the TL (to the nearest $\mathrm{cm}$ ) of each prey item consumed. 
Using an instantaneous sampling method (Altmann 1974), we also recorded lionfish activity at $30 \mathrm{~s}$ intervals during each 30 min observation. Lionfish activity was categorised as either resting (i.e. in contact with the reef, with dorsal spines typically held flat along the dorsal midline) or active. We distinguished 3 categories of 'active' behaviour: hunting, hovering or swimming. Hunting lionfish displayed a stereotypical posture: head down and hovering near prey, pectoral fins spread out and angled forward, dorsal spines erect and tail undulating. Hovering lionfish were nearly motionless above the substratum, but without exhibiting a hunting posture. Swimming lionfish were actively in transit from one part of the reef to another. We also recorded the distance moved (to the nearest $0.5 \mathrm{~m}$ ) by each fish in $30 \mathrm{~s}$ intervals during each observation. The sum of all distances recorded at $30 \mathrm{~s}$ intervals yielded the total distance moved by each lionfish.

To assess variation in prey availability across the day, we conducted a point count of reef fish abundance every 5 min during each $30 \mathrm{~min}$ observation. We estimated and recorded the species, number and TL (to the nearest $\mathrm{cm}$ ) of all fishes, including cryptic fishes, within a $1 \mathrm{~m}$ radius of the focal lionfish. This survey method may have overlooked potential prey items that were hidden within the reef framework; however, such prey items were most likely unavailable to lionfish, which prey by stalking in generally open habitats. We therefore assumed that the potential prey recorded by the divers reflect the minimum prey availability to lionfish.

During the 2 darkest observation periods (the first 30 min of 'dawn' and the last 30 min of 'dusk'), indirect lighting was used to ensure accurate observations of lionfish behaviour and prey availability. Indirect lighting was achieved by partially shielding a dive light with a hand and aiming it at the substratum, $\sim 1 \mathrm{~m}$ away from the focal lionfish. This small amount of lighting could have affected lionfish behaviour and prey availability, thus reducing our ability to detect a relationship between lionfish activity or prey availability and natural changes in ambient light. However, during the 2 periods when lighting was used, lionfish were less active and fewer prey were available as compared with adjacent observation periods (see 'Results'), suggesting that the effect of lighting was limited.

Daily patterns of behaviour and prey consumption. To address the question of whether lionfish prey consumption rates and activity levels are significantly higher during crepuscular hours than at mid-day, we examined dawn-to-dusk variation in 4 aspects of lionfish behaviour. We first assessed the effect of time of day on 2 metrics of lionfish activity, namely active behaviour and hunting behaviour. Fish behaviour was scanned every $30 \mathrm{~s}$ across the $30 \mathrm{~min}$ observation period for each fish. For each fish, we calculated the proportions of scans per $30 \mathrm{~min}$ in which active or hunting behaviour occurred. Then, for each response variable, we created a generalized linear mixed-effects model (Bolker et al. 2009) in which reef sites - a random effect-were nested within time of day (3 categories: dawn, mid-day and dusk) - a fixed effectspecifying binomial distributions for both behaviours. We conducted Bonferroni-corrected Wald $Z$ tests to evaluate differences between the 3 periods of the day.

We then assessed the effect of time of day on lionfish mass-specific prey consumption rates and total distance moved with 2 general linear mixed-effects models (Zuur et al. 2009) in which reef sites (random effect) were nested within time of day (fixed effect). Prey consumption rates and total distance travelled were modelled with a normal error distribution following a log $(x+1)$ transformation to improve homogeneity of variance. We conducted Bonferroni-corrected pair-wise comparisons to evaluate differences between the 3 periods of the day. Mass-specific rate of prey consumption for each lionfish was calculated by first converting TL estimates for each lionfish and its captured prey to biomass. For lionfish, this conversion was performed using scaling constants from a relationship between length $(\mathrm{cm})$ and weight $(\mathrm{g})$ derived from 262 individuals from the Bahamas ranging in size from 6 to $390 \mathrm{~mm}$ (S. Green unpubl. data). For prey fish, we used published estimates of these scaling constants (Froese \& Pauly 2000). When species-specific constants were not available we used estimates for a closely related species. We then divided the total mass of captured prey by the mass of the corresponding lionfish, and expressed prey consumption as mass of prey consumed (g) per mass of lionfish (g) per 30 min period.

Finally, we examined whether high predation rates and activity levels by lionfish coincided with periods of higher prey availability. Based on the distribution of prey sizes consumed by lionfish during our observations, we defined potential prey fish as those individuals $\leq 6 \mathrm{~cm}$ TL. We converted prey TL $(\mathrm{cm})$ to weight $(\mathrm{g})$, and calculated the density of prey fish biomass $\left(\mathrm{g} \mathrm{m}^{-2}\right.$; referred to as available prey biomass) as our measure of prey availability. Available prey biomass was modelled with a normal error distribution following a log $(x+1)$ transformation. We sought to compare the available prey biomass at different times of the day, but the risk of predation by active lionfish could reduce the number of prey fish observed. Alternatively, active lionfish may seek out patches of high prey density. To consider both the effects of time of day and lionfish behaviour on available prey biomass, we created a linear mixed-effects model where time of day (3 categories: dawn, mid-day and dusk) and lionfish behaviour ( 2 categories: active and inactive) were fixed 
effects for measures of available prey biomass associated with each lionfish (random effect), nested within reef site (random effect). We tested for temporal autocorrelation between our point counts by comparing a model that included a residual correlation structure (corAR1) with one that did not, and found that fit was significantly better for the model with the residual correlation structure $\left(\right.$ ANOVA $_{i} \mathrm{df}=7,8, \mathrm{p}=<0.001$,
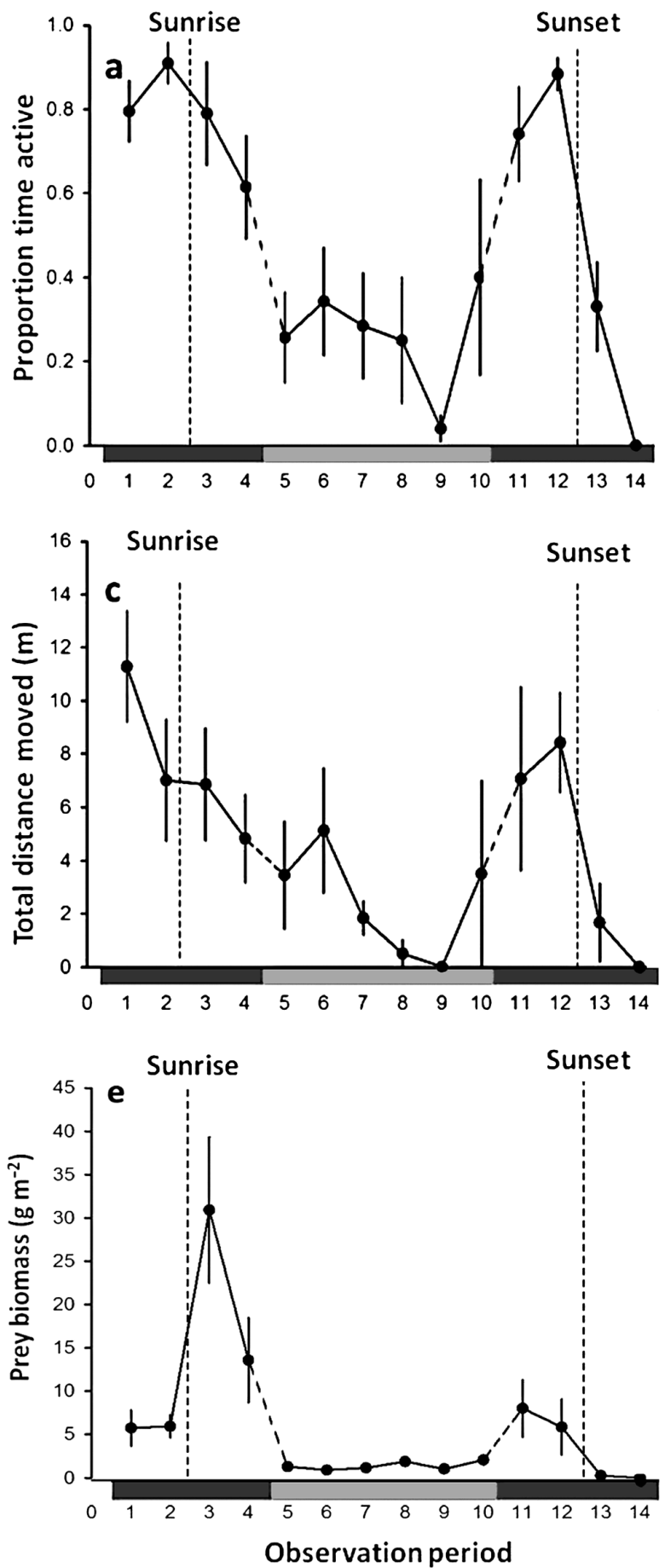

$\mathrm{AIC}_{\mathrm{no} \text { correlation }}=347$ and $\left.\mathrm{AIC}_{\text {correlation }}=335\right)$. We then conducted Bonferroni-corrected pair-wise comparisons to evaluate the differences in available prey biomass between pairs of time periods. We conducted all analyses in R (R Development Core Team 2008), using the package nlme (Pinheiro et al. 2011) for linear mixed-effects models and MASS (Venables \& Ripley 2002) for generalized linear mixed-effects models. We
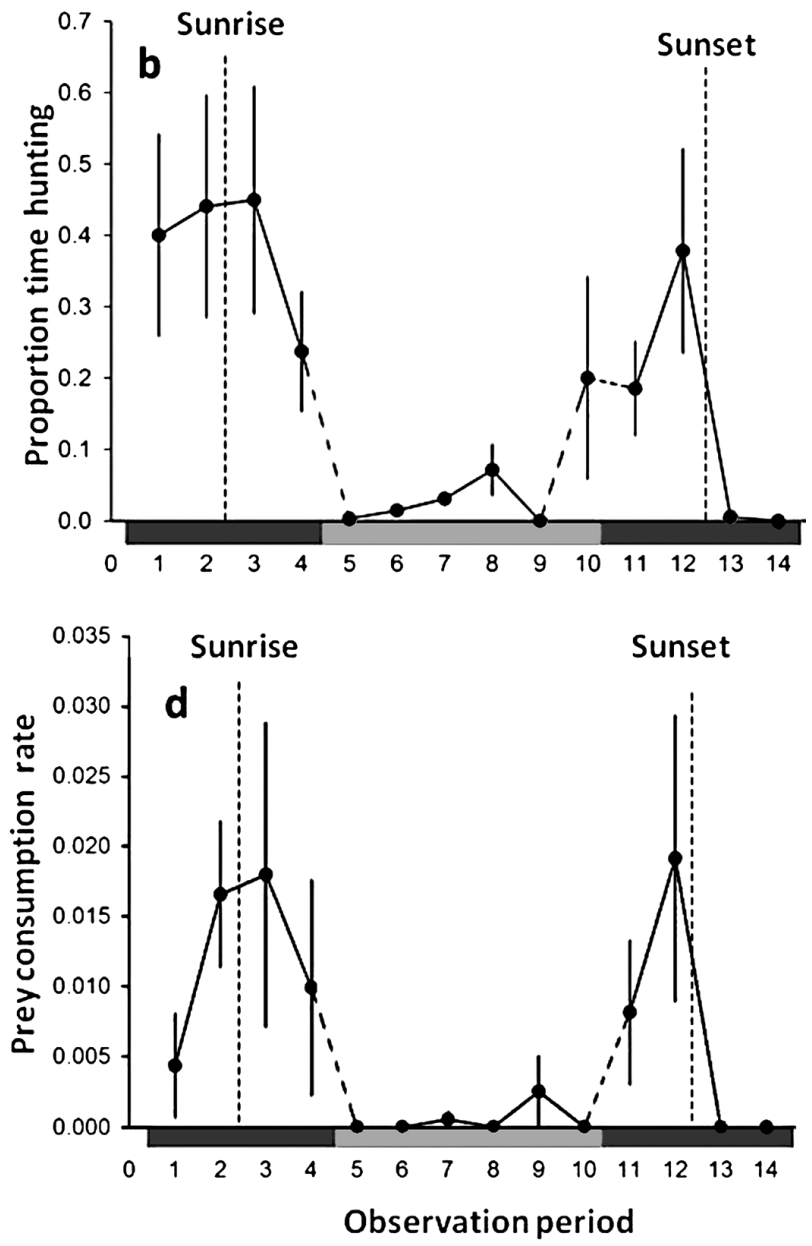

Fig. 1. Pterois volitans. Foraging behaviour and prey consumption rates on patch reefs near Eleuthera, Bahamas, by observation period. (a) Proportion of time active, (b) proportion of time spent hunting, (c) total distance moved (m) per $30 \mathrm{~min},(\mathrm{~d})$ mass-specific consumption rate (g prey per $\mathrm{g}$ lionfish per $30 \mathrm{~min}$ ) and (e) biomass $\left(\mathrm{g} \mathrm{m}^{-2}\right)$ of prey-sized $(\leq 6 \mathrm{~cm}$ TL) reef fishes in the vicinity $(<1 \mathrm{~m}$ distant) of lionfish across the day. Each of the 14 observation periods lasted 30 min. Long dashed lines: breaks in observations between crepuscular and mid-day periods. Short-dashed lines indicate the timing of sunrise and sunset within dawn and dusk crepuscular periods, respectively. All means $\pm \mathrm{SE}$, with $\mathrm{n}=3$ to 10 lionfish per $30 \mathrm{~min}$ period; (e) $\mathrm{n}=18$ to 50 lionfishcentred prey counts per $30 \mathrm{~min}$ period 
estimated overdispersion for each dependent variable using Pearson's residuals (Zuur et al. 2009) and found none. Visual validation of each model (i.e. plots of residual versus fitted values, and boxplots of residuals; Zuur et al. 2009) confirmed that errors were homogeneous and normally distributed.

Daily prey consumption calculation. We estimated the average daily mass-specific rate of prey consumption for lionfish in our study, taking into account daily variation in predation activity. We assumed that lionfish consume prey at rates measured during dawn observations for $\sim 2 \mathrm{~h}$ of the day and, similarly, during dusk observations, for $\sim 2 \mathrm{~h}$ of the day. We assumed that lionfish consumed prey at rates similar to that of our mid-day observations (conducted between 11:00 and 15:00 h) during all non-crepuscular daylight hours ( $~ 9$ h per day). Finally, given the fact that lionfish are visual predators (Fishelson 1997) and that lionfish were completely inactive at night (i.e. between 22:00 and 05:00 h) on 2 reefs where pilot observations were made (L. Akins unpubl. data), we assumed that no predation events occurred at night. Given the frequency of hunting activity observed between dawn and dusk, a low rate of nocturnal predation would lead to only a marginal underestimation of total daily prey consumption.

We constructed a $95 \%$ CI for our estimate of mean daily mass-specific prey consumption from a weighted estimate of variance in the daily rate, which we calculated from our estimates of variance in the rate for each defined period of the day, using the number of hours of prey consumption at each rate as weighting factors.

\section{RESULTS}

On Eleuthera reefs, 92 lionfish ranging in size from 8 to $36 \mathrm{~cm}$ (mean \pm SD: $21 \pm 6$ $\mathrm{cm}$ ) were observed during $46 \mathrm{~h}$ of underwater observation. Activity levels and prey consumption rates closely tracked the daily light cycle (Fig. 1a-d), with all measured aspects of lionfish activity and predation behaviour peaking around sunrise and sunset, and decreasing during mid-day hours (Fig. 1a-d). Available prey biomass in the vicinity of lionfish followed the same pattern, particularly at dawn (Fig. 1e).

All aspects of lionfish behaviour varied significantly among time periods (Fig. $2 \mathrm{a}-\mathrm{d})$. Lionfish spent more time active during both crepuscular periods than at mid-day (Table 1, Fig. 2a). Fifteen lionfish observed during mid-day remained inactive throughout their entire observation period, compared with only 5 individuals during dusk observations and none at dawn. Lionfish also travelled significantly greater distances during the dawn crepuscular period than at mid-day, with distance travelled during the dusk crepuscular period being intermediate to that travelled between dawn and mid-day, and not significantly different from either (Table 1, Fig. 2c). During one dusk observation, a $31 \mathrm{~cm}$ lionfish was observed following and herding a $24 \mathrm{~cm}$ lionfish in apparent courtship across the reef and adjacent sand, travelling at least $23 \mathrm{~m}$. On several occasions, lionfish were observed to move away from the reef, where they were initially observed, to hunt over open sand and seagrass. One individual observed at dusk travelled $130 \mathrm{~m}$ away from the reef, and was still swimming away at the end of the observation period.

Lionfish spent a significantly greater proportion of time hunting, and showed higher mass-specific rates of prey consumption at dawn and dusk than during midday (Table 1, Fig. 2b,d). We observed a total of 45 predation attempts from 25 of the 92 lionfish observed. Of

Table 1. Pterois volitans. Results of post hoc pair-wise comparisons (Bonferroni-corrected Wald $Z$ or $t$-tests) generated for generalized linear mixed models (GLMM) and linear mixed models (LMM) comparing foraging behaviour and available prey biomass at dawn, mid-day, and dusk on coral reefs off Eleuthera, Bahamas. Foraging behaviour was measured through 4 response variables: proportion time active, proportion time hunting, total distance travelled $\left(\mathrm{m}^{2}\right)$ and mass-specific prey consumption rate ( $\mathrm{g}$ prey per $\mathrm{g}$ lionfish per $\mathrm{m}^{2}$ ) for lionfish observed over a $30 \mathrm{~min}$ period during one of the 3 time periods. Available prey biomass $\left(\mathrm{g} \mathrm{m}^{-2}\right)$ was measured as the biomass of prey-sized reef fishes within $1 \mathrm{~m}$ of each lionfish. The model for available prey biomass also included lionfish behaviour (Active or Resting) as an explanatory variable. Bold values indicate significant differences between pairs (i.e. $p_{\text {adjusted }}<0.017$ )

\begin{tabular}{|c|c|c|c|c|}
\hline $\begin{array}{l}\text { Response } \\
\text { variable }\end{array}$ & $\begin{array}{l}\text { Model } \\
\text { type }\end{array}$ & $\begin{array}{l}\text { Test } \\
\text { type }\end{array}$ & $\begin{array}{l}\text { Pair-wise } \\
\text { comparison }\end{array}$ & $\mathrm{p}$-value \\
\hline $\begin{array}{l}\text { Proportion time } \\
\text { active }\end{array}$ & GLMM & Wald $Z$ & $\begin{array}{l}\text { Dawn:Mid-day } \\
\text { Dawn:Dusk } \\
\text { Mid-day:Dusk }\end{array}$ & $\begin{array}{l}\mathbf{0 . 0 1 4} \\
0.463 \\
\mathbf{0 . 0 0 8}\end{array}$ \\
\hline $\begin{array}{l}\text { Proportion time } \\
\text { hunting }\end{array}$ & GLMM & Wald $Z$ & $\begin{array}{l}\text { Dawn:Mid-day } \\
\text { Dawn:Dusk } \\
\text { Mid-day:Dusk }\end{array}$ & $\begin{array}{l}\mathbf{0 . 0 0 1} \\
0.272 \\
\mathbf{0 . 0 0 7}\end{array}$ \\
\hline $\begin{array}{l}\text { Total distance } \\
\text { travelled }\end{array}$ & LMM & $t$-test & $\begin{array}{l}\text { Dawn:Mid-day } \\
\text { Dawn:Dusk } \\
\text { Mid-day:Dusk }\end{array}$ & $\begin{array}{l}\mathbf{0 . 0 1 3} \\
0.449 \\
0.087\end{array}$ \\
\hline $\begin{array}{l}\text { Mass-specific prey } \\
\text { consumption rate }\end{array}$ & LMM & $t$-test & $\begin{array}{l}\text { Dawn:Mid-day } \\
\text { Dawn:Dusk } \\
\text { Mid-day:Dusk }\end{array}$ & $\begin{array}{l}\mathbf{0 . 0 0 5} \\
0.225 \\
\mathbf{0 . 0 1 7}\end{array}$ \\
\hline $\begin{array}{l}\text { Available prey } \\
\text { fish biomass }\end{array}$ & LMM & $t$-test & $\begin{array}{l}\text { Dawn:Mid-day } \\
\text { Dawn:Dusk } \\
\text { Mid-day:Dusk } \\
\text { Resting:Active }\end{array}$ & $\begin{array}{l}\mathbf{0 . 0 0 2} \\
\mathbf{0 . 0 0 2} \\
0.769 \\
0.188\end{array}$ \\
\hline
\end{tabular}



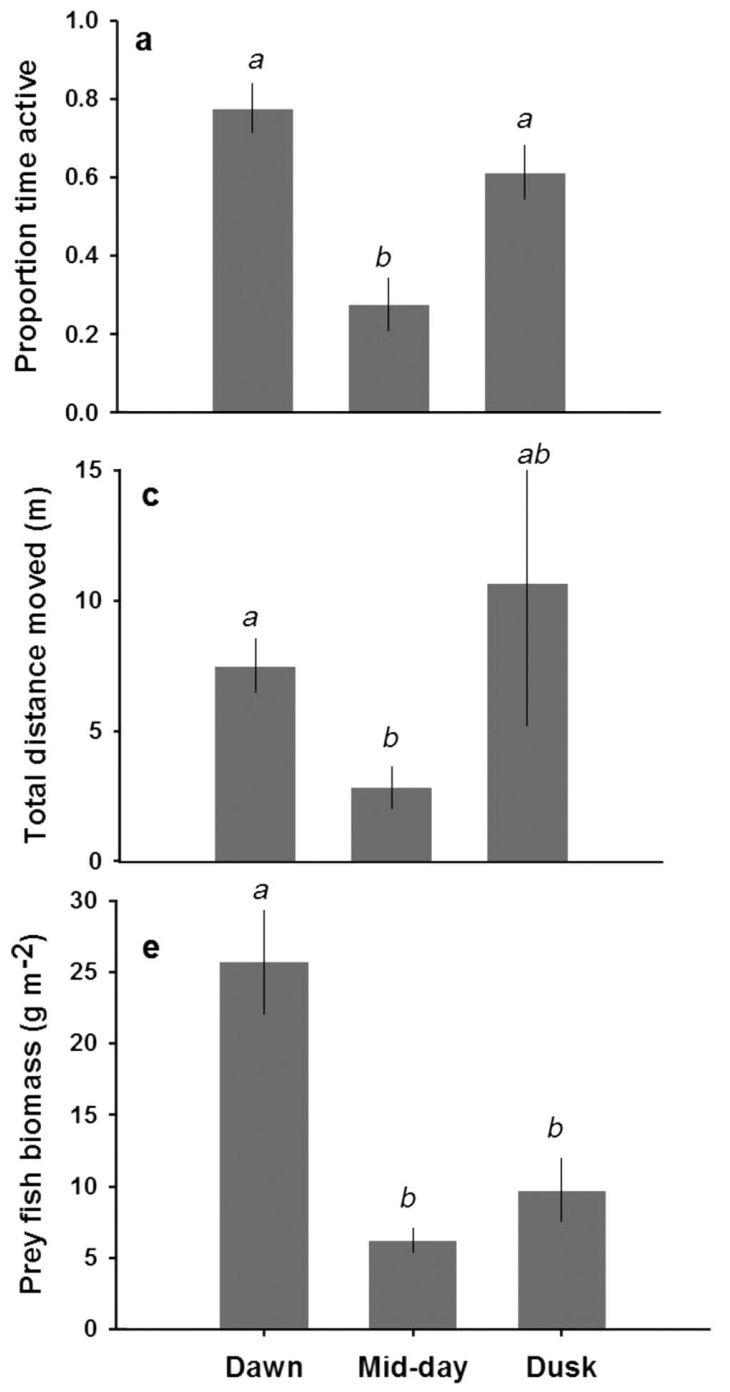

these attempts, only 2 were documented at mid-day, and one of these occurred while the lionfish was stationary on the substratum. Of all strikes at prey, $85 \%$ were successful. The majority of strikes were on reef fishes, with the exception of 3 strikes at small crustacean prey (Table 2). Of the 26 species from 11 families of reef fishes hunted by lionfish, we observed successful captures of individuals from 12 species (Table 2). The average TL of captured prey was $4 \pm$ $1 \mathrm{~cm}$, with a mean body mass of $1.47 \pm 1.58 \mathrm{~g}$.

Time of day had a significant effect on the density of prey-sized reef fishes recorded in the vicinity of lionfish (Table 1, Fig. 2e), while lionfish behaviour (active or resting) did not (Table 1). The biomass of prey-sized fish was significantly higher at dawn than at either mid-day or dusk (Table 1, Fig. 2e).

Taking into account the variable rates of predation observed throughout the day, we estimated that lionfish in our study consumed, on average, $0.089 \mathrm{~g}$ prey
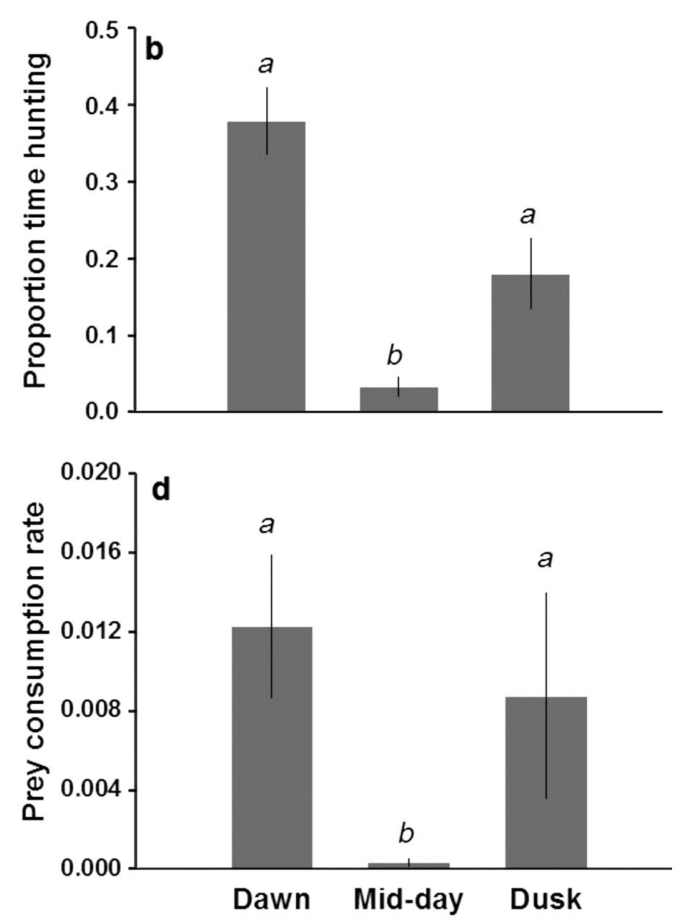

Fig. 2. Pterois volitans. Foraging behaviour and prey consumption rates on patch reefs near Eleuthera, Bahamas, by period of day. (a) Proportion of time active, (b) proportion of time spent hunting, (c) total distance (m) moved per 30 min, (d) mass-specific prey consumption rate ( $\mathrm{g}$ prey per $\mathrm{g}$ lionfish per $30 \mathrm{~min}$ ) and (e) biomass $\left(\mathrm{g} \mathrm{m}^{-2}\right)$ of prey-sized $(\leq 6 \mathrm{~cm} \mathrm{TL})$ reef fishes in the vicinity $(<1 \mathrm{~m}$ distant) of lionfish during each period. Means $\pm \mathrm{SE}$, with $N_{\text {dawn }}=32$ lionfish, $N_{\text {mid-day }}=37$ lionfish, $N_{\text {dusk }}=23$ lionfish; (e) $N_{\text {dawn }}=216$ lionfish-centered prey counts, $N_{\text {mid-day }}=222$ lionfish-centered prey counts, $N_{\text {dusk }}=138$ lionfish-centered prey counts. Within each panel, means with different superscripts were significantly $(p<0.017)$ different from each other in Bonferroni-corrected post hoc tests

per g lionfish per day (95\% CI: from 0.076 to $0.102 \mathrm{~g}$ prey per $g$ lionfish per day). Given the average size of lionfish in this study $(148 \pm 145 \mathrm{~g})$, and the average size of prey, this mass-specific daily consumption rate amounts to, on average, $13 \mathrm{~g}$ prey per lionfish per day (95\% bootstrapped CI: from 12 to $15 \mathrm{~g}$ prey per day).

\section{DISCUSSION}

Lionfish predation behaviour varies significantly throughout the day in their new Atlantic range. Lionfish observed during our study were most active during crepuscular times and the peak in activity during the dawn crepuscular period was associated with high densities of available prey. These observations are consistent with the anecdotal observation of Fishelson (1975), who reported that lionfish in the Red Sea foraged at dawn and dusk, and were mostly inactive dur- 
Table 2. Pterois volitans. Reef fish species and life stages hunted by lionfish on 12 coral reefs off Eleuthera, Bahamas. juv: juvenile fish

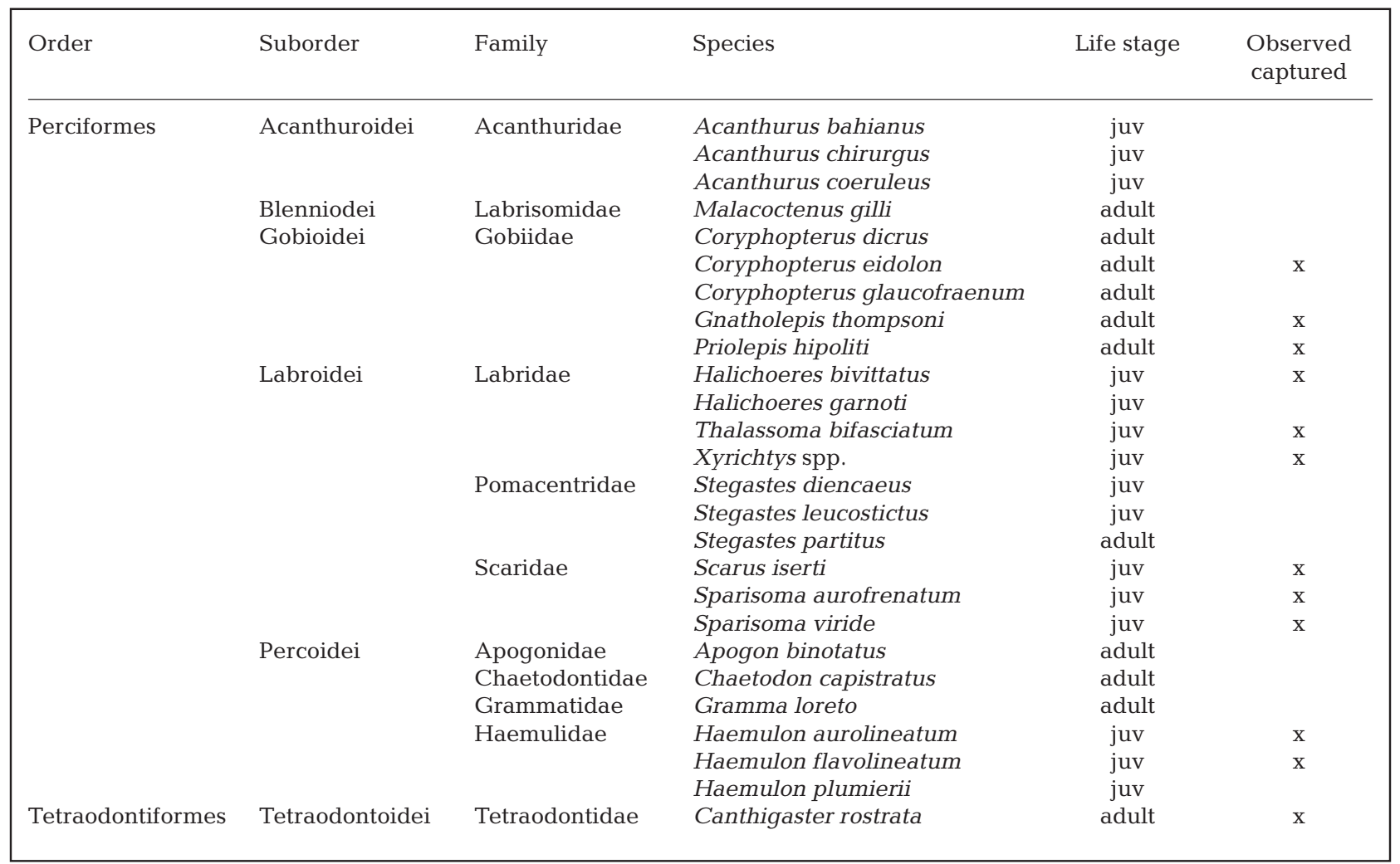

ing the day, sheltering under coral ledges. We also found that all aspects of activity, including the proportion of time spent active, time spent hunting, total distance moved and mass-specific prey consumption rates, were depressed at mid-day on Eleuthera reefs. Taking into account peaks in foraging activity during crepscular periods yields a much higher prey consumption rate than previously estimated for lionfish.

A number of mechanisms could explain the temporal variation in lionfish predatory activity. First, lionfish may hunt only when prey are available. The variation in prey-sized fish biomass documented here, with a peak at dawn, is consistent with daily trends in abundance of coral reef fishes in other regions, where the change-over between diurnal and nocturnal fish communities has been shown to be strongly linked to light level (Hobson 1972, Helfman 1978, 1993, Galzin 1987). However, while we did not observe a similarly large peak in prey biomass at dusk, lionfish observed during this period nevertheless consumed prey at rates similar to those observed over the dawn period. This mismatch may indicate that lionfish prey consumption rates were not limited by access to prey.

A second possible mechanism is that lionfish predatory activity is higher during crepuscular periods because their hunting success is relatively high at low light levels. Better hunting success might result from good visual acuity among lionfish or poor ability by prey fish to detect the presence of these predators under low light conditions. In either case, we would expect the proportion of prey captured by lionfish to be higher during crepuscular periods than at mid-day and to be equally high at dawn and dusk with equivalent low-light levels. While the scarcity of predation attempts by lionfish during mid-day observations prohibits a thorough comparison of capture success between crepuscular and mid-day conditions, capture success was indeed high and similar at dawn $(85 \%$ of attempts successful) and dusk (88\% successful). Studies quantifying capture success by fish predators in relation to light availability are needed to elucidate the importance of this mechanism for explaining variation in hunting activity across the day. However, the observation of frequent daytime hunting by lionfish on overcast days (Côté \& Maljković 2010), when light levels may have approximated crepuscular conditions, suggests that light levels are an important factor controlling lionfish activity.

A third possible mechanism is the contribution of satiation to daily variation in lionfish hunting patterns. Satiation has been shown to affect the predation rates of piscivorous fish because short-term storage capacity 
in the stomach has been exceeded (Essington et al. 2000). However, preliminary laboratory studies of lionfish digestion rates of the Atlantic pinfish Lagodon rhomboides have revealed that prey are not substantially broken down after $8 \mathrm{~h}$ in the gut (J. A. Morris pers. comm.). If prey digestion time is longer than the interval between crepuscular periods, the high rates of prey consumption we observed at both dusk and dawn suggest that lionfish may not feed to satiation in a single foraging bout. Instead, they may partition their feeding activities between the 2 crepuscular periods each day, in which case their prey consumption is limited by other factors, such as prey availability and capture success.

A final explanation for the patterns of foraging behaviour we observed may be that lionfish time their activities to escape detection by visually oriented predators. However, we did not observe any encounters between lionfish and potential predators (e.g. sharks, large groupers or eels). Given that lionfish have venomous spines and are a relatively novel species in the Caribbean, it is unlikely that predation threat in their invaded range controls their foraging behaviour.

Our study highlights the importance of considering daily environmental variation when assessing prey consumption rates. Our estimate of daily mass-specific rate was $0.089 \mathrm{~g}$ prey per $\mathrm{g}$ lionfish per day (95\% CI: from 0.076 to $0.102 \mathrm{~g}$ prey per $\mathrm{g}$ lionfish per day). Prior to our study, 2 estimates of lionfish prey consumption rates were available. A bioenergetics experiment with Red Sea lionfish Pterois miles, fed ad libitum, reported much lower average daily mass-specific prey consumption rates than ours, viz. from 0.02 to $0.06 \mathrm{~g}$ prey per $g$ lionfish per day (Fishelson 1997), suggesting that captivity affects energy requirements and may result in under-estimates of prey consumption. In contrast, observations of Bahamian lionfish in the wild but taken only during mid-day periods yielded $0.038 \mathrm{~g}$ prey per $\mathrm{g}$ lionfish per day (Côté \& Maljković 2010). Our estimate is therefore $\sim 3$ times larger than that of the previous in situ study. Although some of the difference between the 2 in situ estimates may be attributed to differences in average lionfish mass (148 $\mathrm{g}$ in our study versus $340 \mathrm{~g}$ in Côté \& Maljković 2010) and water temperature (on average, $26^{\circ} \mathrm{C}$ in our study versus $23^{\circ} \mathrm{C}$ in Côté \& Maljković 2010), most is likely explained by our consideration of crepuscular peaks in hunting activity. Increasing the accuracy of prey consumption estimates will allow ecologists to better predict the impacts of lionfish on native fish communities. Our study thus provides valuable estimates of mass-specific predation rates of lionfish on native Caribbean fishes that can be used in conjunction with estimates of prey production to quantify the effect of lionfish predation on Caribbean reef fish.
Acknowledgements: We thank D. and T. Ferguson for generously donating logistical support for this study, and A. Oronti, K. Hayward, K. Ambrose and J. Stokely at the Cape Eleuthera Institute for their assistance in the field. Thanks to E. Darling for helpful comments on the manuscript. This study was funded by a Canada Graduate Scholarship from the Natural Sciences and Engineering Research Council (NSERC) of Canada to S.J.G. and an NSERC Discovery Grant to I.M.C.

\section{LITERATURE CITED}

Albins MA, Hixon MA (2011) Worst case scenario: potential long-term effects of invasive predatory lionfish (Pterois volitans) on Atlantic and Caribbean coral-reef communities. Environ Biol Fishes, doi: 10.1007/s10641-011-9795-1

Altmann J (1974) Observational study of behaviour: sampling methods. Behaviour 49:227-267

Bolker BM, Brooks ME, Clark CJ, Geange SW, Poulsen JR, Stevens HH, White JSS (2009) Generalized linear mixed models: a practical guide for ecology and evolution. Trends Ecol Evol 24:127-135

Connell SD (1998) Patterns of piscivory by resident predatory reef fish at One Tree Reef, Great Barrier Reef. Mar Freshwater Res 49:25-30

Côté IM, Maljković A (2010) Predation rates of Indo-Pacific lionfish on Bahamian coral reefs. Mar Ecol Prog Ser 404: 219-225

Essington TE, Hodgson JR, Kitchell JF (2000) Role of satiation in the functional response of a piscivore, largemouth bass (Micropterus salmoides). Can J Fish Aquat Sci 57:548-556

Fishelson L (1975) Ethology and reproduction of pteroid fishes found in the Gulf of Aqaba (Red Sea), especially Dendrochirus brachypterus (Cuvier) (Pteroidae, Teleostei). PSZNI: Mar Ecol 39:635-656

Fishelson L (1997) Experiments and observations on food consumption, growth and starvation in Dendrochirus brachypterus and Pterois volitans (Pteroinae, Scorpaenidae). Environ Biol Fishes 50:391-403

Fonds M, Cronie R, Vethaak AD, Van Der Puyl P (1992) Metabolism, food consumption and growth of plaice (Pleuronectes platessa) and flounder (Platichthys flesus) in relation to fish size and temperature. Neth J Sea Res 29: $127-143$

Froese R, Pauly D (eds) (2000) FishBase: 2000: concepts, design and data sources. ICLARM, Los Baños

Galzin R (1987) Structure of fish communities of French Polynesian coral reefs. II. Temporal scales. Mar Ecol Prog Ser 41:137-145

Goldberg J, Wilkinson C (2004) Global threats to coral reefs: coral bleaching, global climate change, disease, predator plagues, and invasive species. In: Wilkinson C (ed) Status of Coral Reefs of the World, Vol 1. Australian Institute of Marine Science, Townsville, Queensland, Australia, p 67-92

Helfman GS (1978) Patterns of community structure in fishes: summary and overview. Environ Biol Fishes 3:129-148

Helfman GS (1993) Fish behaviour by day, night and twilight. In: Pitcher TJ (ed) Behaviour of teleost fishes, 2nd edn. Chapman \& Hall, London, p 479-512

Hobson ES (1972) Activity of Hawaiian reef fishes during the evening and morning transitions between daylight and darkness. Fish Bull 70:715-740

Hobson ES (1973) Diel feeding migrations in tropical reef fishes. Helgoländer Wiss Meeresunters 24:361-370

Luckhurst BE, Luckhurst K (1978) Analysis of the influence of substrate variables on coral reef fish communities. Mar 
Biol 49:317-323

Mooney HA, Cleland EE (2001) The evolutionary impact of invasive species. Proc Natl Acad Sci USA 98:5446-5451

Morris JA, Akins JL (2009) Feeding ecology of invasive lionfish (Pterois volitans) in the Bahamian archipelago. Environ Biol Fishes 86:389-398

Morris JA, Whitfield PA (2009) Biology, ecology, control and management of the invasive Indo-Pacific lionfish: an updated integrated assessment. Tech Mem NOS NCCOS 99. National Oceanic and Atmospheric Administration, Washington, DC

Pinheiro J, Bates D, DebRoy S, Sarkar D, R Development Core Team (2011) nlme: Linear and nonlinear mixed effects models. R package version 3.1-100. http://CRAN.R-project. org/package=nlme

R Development Core Team (2008) R: a language and environment for statistical computing. R Foundation for Statistical Computing, Vienna, Austria http://www.R-project.org

REEF (2011) Reef Environmental Education Foundation volunteer survey project database. http://www.reef.org. Ac-

Editorial responsibility: Charles Birkeland,

Honolulu, Hawaii, USA cessed January 2011

Sutherland WJ, Clout M, Côté, IM, Daszak, P and others (2010) A horizon scan of global conservation issues for 2010. Trends Ecol Evol 25:1-7

Sweatman HP (1984) A field study of the predatory behavior and feeding rate of a piscivorous coral reef fish, the lizardfish Synodus englemani. Copeia 1984:187-194

Venables WN, Ripley BD (2002) Modern applied statistics with S, 4th edn. Springer, New York, NY

Vincent SE, Mori A (2008) Determinants of feeding performance in free-ranging pit- vipers (Viperidae: Ovophis okinavensis): key roles for head size and body temperature. Biol J Linn Soc 93:53-62

Yamashita N, Stoner KE, Riba-Hernandez P, Dominy NJ, Lucas PW (2005) Light levels used during feeding by primate species with different color vision phenotypes. Behav Ecol Sociobiol 58:618-629

Zuur AF, Ieno EN, Walker NJ, Saveliev AA, Smith GM (2009) Mixed effects models and extensions in ecology with $\mathrm{R}$. Springer, New York, NY

Submitted: October 28, 2010; Accepted: May 12, 2011

Proofs received from author(s): July 1, 2011 